\title{
USO DO CELULAR COMO INTERFACE PEDAGÓGICA PARA MEDIAR A CONSTRUÇÃO DO CONHECIMENTO NA EJA
}

\author{
USING THE CELL PHONE AS A PEDAGOGICAL INTERFACE TO \\ MEDIATE KNOWLEDGE CONSTRUCTION IN EJA
}

\section{UTILIZACIÓN DEL TELÉFONO CELULAR COMO UNA INTERFAZ PEDAGÓGICA PARA MEDIAR LA CONSTRUCCIÓN DEL CONOCIMIENTO EN EJA}

\author{
Madryracy Ferreira Coutinho Medeiros Ovídio ${ }^{1}$ \\ Maria Olivia Matos Oliveira ${ }^{2}$ \\ Antonio Amorim ${ }^{3}$
}

\begin{abstract}
RESUMO
Este estudo é o resultado de uma pesquisa realizada com os estudantes do Ensino Fundamental noturno, da modalidade de Educação de Jovens e Adultos (EJA), com o intuito de diagnosticar os motivos e desdobramentos do uso dos aparelhos celulares nas aulas pelos estudantes jovens e adultos; refletir sobre as possibilidades do uso do celular como interface pedagógica para mediar a construção do conhecimento na EJA e propor algumas alternativas de como explorar os recursos didáticos de um telefone celular em turmas de EJA. Na pesquisa de campo utilizou-se como instrumento de recolha dos dados a observação indireta através da roda de conversa com um roteiro medianamente estruturado, aplicação das oficinas, as notas de campo e os registros fotográficos. Os principais resultados obtidos foram os seguintes: ficou evidente que no município de Serrinha não há leis e regulamentos escolares na rede pública municipal que proíbem o uso dos aparelhos celulares na escola, entretanto, é o (a) professor (a) que determina as regras de uso na sala de aula. Constatou-se
\end{abstract}

\footnotetext{
1 Doutoranda do Programa de Pós-Graduação em Educação e Contemporaneidade - PPGEduC/UNEB. Mestrado em Educação de Jovens e Adultos_ MPEJA/UNEB. Especialista em Supervisão Escolar UEFS. Professora Auxiliar da Universidade do Estado da Bahia (UNEB) . Coordenadora de Pesquisa e Estágio em Espaços Não Escolares, Educação Infantil e Anos Iniciais do Ensino Fundamental. Pesquisadora dos Grupos de Pesquisa Gestão, Organização, Tecnologias e Políticas Públicas em Educação - GP-GEPE e Teoria Social e Projeto Político Pedagógico - TSPPP/PPGEduc-UNEB. E-mail madrycoutinho@ hotmail.com

${ }^{2}$ Professora do DEDCI e da Pós-Graduação em Educação e Contemporaneidade (PPGEduC) e do Mestrado Profissional em Educação de Jovens e Adultos (MPEJA), da Universidade do Estado da Bahia. Pesquisadora de processos formativos a distância e tecnologias aplicadas a Educação Uma das líderes do grupo de pesquisa: Sociedade em Rede, Pluralidade e Conteúdos Digitais Educacionais. E-mail mariaoliviamatos@ gmail.com

${ }^{3}$ Professor Titular Pleno da Universidade do Estado da Bahia - UNEB. Programa de Pós-graduação Mestrado Profissional em Educação de Jovens e Adultos (MPEJA). Líder do Grupo de Pesquisa Gestão, Organização e Política Públicas em Educação - GP- GEPE. E-mail: antonioamorim52@gmail.com
} 
também que, os estudantes jovens e adultos quando estão em aula vaga ou entediados com as aulas usam seus celulares para ouvirem músicas, assistirem vídeos, entrarem nas redes sociais para comunicar-se. Cabe a escola, portanto, compreender as questões culturais e sociais relativas a este comportamento habitual dos jovens e adultos e que o uso perspicaz da tecnologia na sala de aula pode favorecer um ambiente de aprendizado mais colaborativo e envolvente para os estudantes jovens e adultos.

Palavras-chave: Educação de Jovens e Adultos. Telefone celular. Construção do conhecimento. Interface pedagógica.

\begin{abstract}
This study is the result of a research carried out with the students of the evening Elementary School, of the Youth and Adult Education (EJA), in order to diagnose the reasons and consequences of the use of the cell phone devices in the classes by the young and adult students; to reflect on the possibilities of using mobile phones as a pedagogical interface to mediate the construction of knowledge in EJA and to propose some alternatives on how to explore the didactic resources of a cell phone in EJA classes. In the field research we used as instrument of data collection the indirect observation through the conversation wheel with a medium structured script, application of the workshops, the field notes and the photographic records. The main results obtained were as follows: it was evident that in the municipality of Serrinha there are no school laws and regulations in the municipal public network that prohibit the use of cell phone devices in school, however, it is the teacher who determines the rules of use in the classroom. It has also been found that young and adult students when in class or bored with class use their cell phones to listen to music, watch videos, join social networks to communicate. It is therefore up to the school to understand the cultural and social issues relating to this habitual youth and adult behavior and that insightful use of technology in the classroom can foster a more collaborative and engaging learning environment for young and adult students.
\end{abstract}

Key words: Youth and adult education; cell phone; knowledge building. Pedagogical interface.

\title{
RESUMEN
}

Este estudio es el resultado de una investigación realizada con los estudiantes de la Escuela Primaria vespertina, de la Educación de Jóvenes y Adultos (EJA), con el fin de diagnosticar las razones y consecuencias del uso de dispositivos móviles en las clases por parte de los estudiantes jóvenes y adultos. ; reflexionar sobre las posibilidades de utilizar los teléfonos móviles como una interfaz pedagógica para mediar en la construcción del conocimiento en EJA y proponer algunas alternativas sobre cómo explorar los recursos didácticos de un teléfono móvil en las clases de EJA. En la investigación de campo utilizamos como instrumento de recolección de datos la observación indirecta a través de la rueda de conversación con un guión estructurado medio, la aplicación de los talleres, las notas de campo y los registros fotográficos. Los principales resultados obtenidos fueron los siguientes: era evidente que en el municipio de Serrinha no existen leyes y reglamentos escolares en la red pública municipal que prohíban el uso de dispositivos móviles en la escuela, sin embargo, es el maestro quien determina las reglas. de uso en el aula. También se ha encontrado que los estudiantes jóvenes y adultos cuando están en clase o aburridos usan sus teléfonos celulares para escuchar música, ver videos, unirse a las redes sociales para comunicarse. Por lo tanto, corresponde a la escuela comprender los problemas culturales y sociales relacionados con este comportamiento habitual de jóvenes y adultos y que el uso 
perspicaz de la tecnología en el aula puede fomentar un entorno de aprendizaje más colaborativo y atractivo para estudiantes jóvenes y adultos.

Palabras clave: Educación de Jóvenes y Adultos. Teléfono celular. Construcción de conocimiento. Interfaz pedagógica.

\section{INTRODUÇÃO}

Este estudo é o resultado de uma experiência pedagógica na Educação de Jovens e Adultos (EJA), da Escola Maria Áurea Pimentel Ferreira, da Rede Municipal de Ensino, do Município de Serrinha/BA. O trabalho foi desenvolvido no sentido de desmistificar o alegado desserviço dos celulares para o bom desenvolvimento das aulas, gerando dilemas e até proibições para o seu uso nos espaços escolares.

A pesquisa surgiu da polêmica sobre o uso do aparelho celular pelos estudantes jovens e adultos durante e fora das aulas. Alguns/algumas docentes, se posicionavam contrários ao seu uso pela facilidade de troca de respostas durante as avaliações, pela distração que causa aos estudantes durante as aulas e até proibiam o uso dos celulares durante as suas aulas. Outros/outras docentes, se posicionavam a favor salientando que esses aparelhos, com o seu imenso poder de convergência, integram recursos que podem dinamizar o processo de construção do conhecimento da EJA, instigando para melhoria da aprendizagem dos estudantes jovens e adultos. Observa-se neste contexto, que há professores/professoras que proíbem e outros que liberam o uso de celulares na sala de aula.

Assim, pelos aspectos sinalizados, levantamos o seguinte questionamento: Quais os motivos, as possibilidades do uso do aparelho celular na sala de aula e de que modo utilizar o telefone móvel (celular) para potencializar as aprendizagens dos/das estudantes da EJA? Diante deste cenário, a pesquisa foi concebida objetivando diagnosticar os motivos e desdobramentos do uso dos aparelhos celulares nas aulas pelos/pelas estudantes jovens e adultos; refletir sobre as possibilidades do uso do celular como interface pedagógica para mediar a construção do conhecimento na EJA e propor algumas alternativas de como explorar os recursos didáticos de um telefone celular em turmas de EJA.

Como referencial teórico, dialogamos com autores que abordam a temática: Moran (2008) que revela a ausência de propostas mais adequadas à sociedade da informação e do conhecimento nas escolas. Castells (2009), destaca que os telefones celulares têm se tornado uma das tecnologias mais utilizadas atualmente, comum em todas as idades, etnias e classes sociais, o que demonstra o potencial do uso desta tecnologia. Silveira (2009), sugere que ao 
invés de proibir porque temos problemas por uso indevido nas escolas, devemos aproveitar para ensinar como as pessoas devem se portar com o celular. Côrtes (2009), defende que atualmente, não podemos mais adiar o encontro com as tecnologias; passíveis de aproveitamento didático, uma vez que os estudantes estão voluntariamente e entusiasticamente imersos nestes recursos - já falam outra língua, pois desenvolveram competências explicitadas para conviver com elas.

$\mathrm{Na}$ pesquisa de campo utilizou-se como instrumento de recolha dos dados a observação indireta através da roda de conversa com um roteiro medianamente estruturado, com o objetivo de os pesquisadores obterem informações sobre a visão dos estudantes da Escola Maria Áurea Pimentel Ferreira (EMAPF) sobre os motivos e as possibilidades da utilização do aparelho celular nas aulas da EJA. Durante o bate papo na roda de conversa, os sujeitos interviram na produção da informação. Como instrumento de observação direta, foram utilizados durante a aplicação das oficinas, notas de campo e registros fotográficos feito com aparelho celular, onde os pesquisadores fizeram a recolha das informações, sem se dirigir aos sujeitos interessados.

A pesquisa de campo e a oficina realizada na escola, nos revelam que no município de Serrinha não há leis e regulamentos escolares na rede pública municipal que proíbem o uso dos aparelhos celulares na escola, entretanto, é o (a) professor (a) que determina as regras de uso na sala de aula. Constatou-se também que, os estudantes jovens e adultos quando estão em aula vaga ou entediados com as aulas usam seus celulares para ouvirem músicas, assistirem vídeos, entrarem nas redes sociais para comunicar-se. Cabe a escola, portanto, compreender as questões culturais e sociais relativas a este comportamento habitual dos jovens e adultos, contribuindo para um ambiente de aprendizado mais colaborativo e envolvente para estes estudantes.

O trabalho encontra-se estruturado em partes. Esta introdução que evidencia a problemática e a relevância da pesquisa. O segundo tópico traz a discussão sobre a escola e o uso das Tecnologias da Informação e Comunicação Móveis e sem fio (TIMS). Em seguida, apresenta a investigação sobre o uso do celular na EJA. Logo após, são descritos e analisados a "Vivência do uso do aparelho celular como recurso didático para mediar a construção do conhecimento na EJA" fazendo uma reflexão sobre o uso didático do celular no contexto escolar da EJA e, por último, as considerações e recomendações refletindo sobre a realização deste trabalho apontando alguns caminhos possíveis para o uso perspicaz da tecnologia móvel na sala de aula, favorecendo um ambiente de aprendizado mais colaborativo e envolvente para estudantes jovens e adultos. 


\section{A ESCOLA E O USO DAS TECNOLOGIAS DA INFORMAÇÃO E COMUNICAÇÃO MÓVEIS E SEM FIO (TIMS)}

O processo educativo vai além do espaço educativo formal ofertado pela escola. Entretanto, na escola podemos estimular o pensamento crítico, criativo, fortalecendo a formação cidadã ou vivenciar circunstâncias mais restritivas e opressoras da liberdade do pensamento. Segundo Freire (2008), a educação deve ser desinibidora e não restritiva, estimulando os estudantes para que sejam eles mesmos.

A escola foi eleita pela sociedade como espaço formal indicada para sistematização do conhecimento. O que vimos com o passar dos anos é que a escola segue rituais rígidos de transmissão de conhecimentos e com medo do diferente, mantém relações autoritárias e resistentes em busca de novos e diferentes caminhar. Moran (2008) considera que mantemos algo que já não acreditamos completamente, mas não ousamos incorporar novas propostas mais adequadas a sociedade da informação e do conhecimento, cada vez mais presente.

Somos obrigados a (con) viver numa conjuntura constantemente contraditória: de um lado, comportamentos, propostas pedagógicas e currículos cristalizados; de outro o enorme crescimento de novas tecnologias e o acesso a estas tecnologias pelos estudantes. Com isso, podemos afirmar que a escola precisa evoluir, precisa ser repensada, precisa está ligada à vida, ao cotidiano dos seus estudantes para fazer sentido, ter significado, ser contextualizada.

O uso das Tecnologias da Informação e Comunicação Móveis e Sem Fio (TIMS) avolumam os desafios da realidade escolar e os educadores necessitam se adequar a realidade desenhada pelas TIMS. Entre as TIMS, temos o celular, um aparelho popular, com aplicativos que podem vir a ser utilizados em sala de aula como recurso pedagógico.

A Agência Nacional de Telecomunicações (ANATEL), revelou que em janeiro de 2017 havia no Brasil 243,4 milhões de linhas ativas na telefonia móvel e teledensidade de 117,65 acessos por 100 habitantes. Associam-se o crescimento do setor ao aumento da renda da população, uma aparente predisposição cultural dos consumidores em adotarem novas tecnologias e pelo déficit de linhas telefônicas convencionais.

Os telefones celulares têm se tornado um aparelho central na construção da identidade dos jovens (CASTELLS et al., 2009). Estes costumam ser mais rápidos ao se apropriar das tecnologias móveis, pois habituam usá-la com intensidade para gravar vídeos, tirar fotos, gravar voz, reproduzir arquivo, ter acesso à internet, às redes sociais, entre outros propósitos. Apesar de muito utilizada pelos jovens, tornou-se também uma das tecnologias 
mais utilizadas atualmente, comum em todas as idades, etnias e classes sociais, o que demonstra o potencial do uso desta tecnologia. Outro aspecto importante a considerar como afirma Ribas, et al.,

É o poder de convergência que o aparelho celular apresenta, integrando vários recursos como a internet, câmera fotográfica, filmadora, calculadora, relógio, cronometro, gravador de voz, rádio, GPS, e-mail, computador, SMS, wi-fi, editores de textos, softwares, calendário, bluetooth, entre outros, que podem dinamizar todo processo de ensino, proporcionando ao educador recursos didáticos que o tornam indispensáveis para a sala de aula da realidade atual (...). (RIBAS, et al., 2012, p. 2).

Apesar de possuírem vários recursos que podem dinamizar o processo de ensino, passaram a ser vistos, pela gestão e pelos docentes de muitas escolas, como um vilão, que atrapalham as aulas. Em alguns estados são proibidos em sala de aula por lei, em outros são proibidos pelos gestores e professores, no entanto, com a censura perde a educação. Nessa direção, Silveira (2009) afirma que não tem sentido negar o acesso dos estudantes a um meio de comunicação que vem adquirindo cada vez mais importância na sociedade. Ao invés de proibir porque temos problemas por uso indevido nas escolas, devemos aproveitar para ensinar como as pessoas devem se portar com o celular. Costa (2012) ressalta, para tentar compreender hoje os dilemas e impasses do uso do aparelho celular no contexto escolar é necessário entender, a priori, que "com a invasão do celular na escola, seu baixo custo e facilidade, seria um grande desperdício deixá-lo de lado ou mesmo tentar retirá-lo do espaço escolar, pois esse equipamento pode ser utilizado para o avanço do processo ensinoaprendizagem". ( p. 34). Assim como Silveira e Costa, Côrtes também defende que "atualmente, não podemos mais adiar o encontro com as tecnologias; passíveis de aproveitamento didático, uma vez que os alunos voluntários e entusiasticamente imersos nestes recursos - já falam outra língua, pois desenvolveram competências explicitadas para conviver com elas". ( 2009, p. 18).

Assim, a utilização do celular na educação não se trata de uma questão de opção, mas uma exigência desta sociedade. Por outro lado, ainda é importante destacar que é urgente que o professor supere os obstáculos e busque atuar afinado com as tecnologias. Mas, como utilizar o aparelho celular na sala de aula para potencializar as aprendizagens dos estudantes?

Conforme Souza (2009), através do celular, o professor tem possibilidade de interagir com seus educandos enviando link's, arquivos de vídeos, imagens, músicas e até 
atividades extraclasse; produzindo materiais a serem utilizados na sala de aula, como gravação de vídeo, documentários. Além dos recursos comuns dos celulares que podem ser explorados como calculadora, cronômetro, tradutor, câmera fotográfica e filmadora, calendários.

$\mathrm{Na}$ aula de matemática, a calculadora pode ser utilizada como uma forma de conferir os resultados, para resolver algumas frações e equações antes, para saber o resultado que se deve obter no final da conta antes de fazê-las em seu livro e caderno. O cronômetro como é um marcador de tempo, serve para saber quanto tempo leva para turma resolver uma situação problema. O tradutor que pode ser utilizado como dicionário na aula de língua portuguesa, é/será um modo mais fácil que o dicionário na versão impressa, já que tem a vantagem da portabilidade; mas não que o dicionário fique de lado, ele também pode ser utilizado normalmente por aqueles que preferirem. A câmera, pode ser utilizada como uma forma de registrar as cenas de uma apresentação, por exemplo, e mandar para o blog da escola direto do celular, a filmadora também poderá ser bem útil a filmar cada apresentação, assim como o gravador que pode auxiliar nas gravações das entrevistas realizadas pelos estudantes.

No lugar da obrigação burocrática em torno das atividades de aprendizagem, valorizar o interesse na troca e na co-criação da aprendizagem e da comunicação. Cada professor, com seus aprendizes, pode criar possibilidades, as mais interessantes e diversas. Antonio (2010) evidencia outras experiências e sugestões pedagógicas para o uso pedagógico dos telefones moveis em sala de aula e fora dela:

(...) se você marca entregas de trabalho ou outras datas que considera importante que os alunos se lembrem, peça-lhes que anotem essas datas (...) na agenda do celular que tem mecanismos de alerta. Já é possível criar serviço de envio de mensagens de aviso por e-mail ou via torpedo. Pelo celular é possível receber atualizações de sites, blogs e até mesmo de mensagens, bem como fazer o caminho oposto. Se quiser dar um passo adiante você pode criar um serviço desses e disponibilizar para seus alunos; o telefone celular também é um serviço de leitura de notícias e de publicação de notícias (p. 05)

Fica evidente, nos estudos realizados que a tecnologia da informação e comunicação fazem parte da vida dos jovens e adultos e por isso mesmo, devemos utilizá-la a nosso favor, para envolver o estudante com seu processo de aprendizagem, reconhecendo seus conhecimentos e suas experiências. Outra questão, é que as escolas públicas sofrem pela falta de estrutura e recursos tecnológicos que poderiam ser supridos pelo uso dos aparelhos 
celulares que os estudantes carregam e que com vimos anteriormente, dispõem de uma infinidade de funções.

O celular pode e deve ser utilizado como interface no processo ensino-aprendizagem, porém precisamos estar atentos a algumas situações: Ainda temos alguns estudantes que não têm telefone celular ou que têm telefones celulares que não dispõem de todos os recursos mencionados aqui; muitas escolas não possuem um sistema que dê acesso aos educandos para usar a internet em seus aparelhos. Portanto, é preciso propor atividades que envolvam o uso de celulares para grupos de estudantes em que pelo menos um do grupo disponha do celular com o recurso que será utilizado; possibilitar que os estudantes aprendam a usar o recurso antes de propô-lo como parte de uma atividade (Geralmente os estudantes dominam os celulares melhor do que seus professores e aprendem rápido a usá-lo, por isso é uma boa ideia "deixar que eles mesmos ensinem e aprendam a usar o recurso entre eles mesmos"), também é importante discutir as questões éticas e morais envolvidas no uso de imagens e registros, bem como o uso indevido dos celulares e de outros equipamentos de mídia assegurando seu uso responsável.

\section{UMA INVESTIGAÇÃO SOBRE O USO DO CELULAR NA EJA}

A escola escolhida para investigação está localizada em um bairro periférico do município de Serrinha/Bahia. Atualmente a escola funciona nos três turnos: pela manhã e à tarde, atende estudantes do ensino Fundamental (Anos finais); pela noite, aos estudantes da modalidade da Educação de Jovens e Adultos (Ensino Fundamental- Estágio II), assim como nas outras escolas da EJA no município. A escolha pela escola municipal e pelos estudantes da EJA baseia-se em três fatores relevantes: pela proximidade com os sujeitos envolvidos; pela presença gigantesca do celular na sala de aula pelas mãos dos estudantes e, finalmente, por observarmos educadores apresentando resistência a este uso. Por esses aspectos, investigou-se o uso do celular como interface pedagógica para mediar a construção do conhecimento na EJA.

A unidade escolar é considerada de grande porte, pois, conta com 11 salas de aulas. $\mathrm{Na}$ EJA, o processo educativo é distribuído em etapas, ofertadas em cinco dias da semana, com duração média de três horas. O grupo de servidores da escola na EJA é formado por: Uma diretora, uma vice-diretora, um secretário, um agente administrativo, um porteiro, dois vigilantes, uma merendeira, um professor e 06 professoras. 
O público da EJA que frequenta a escola são estudantes jovens e adultos trabalhadores, na faixa etária entre 16 a 50 anos de idade, do Ensino Fundamental II. A maioria dos estudantes são principalmente jovens, do sexo masculino, negros, de baixa renda e trabalhadores que vão direto do trabalho para a escola. Esses sujeitos possuem trabalho informal e atuam como: vendedor ambulante, funcionárias do lar, diarista, pedreiro, ajudante de pedreiro, funcionários da fábrica e dos ateliês de calçados. O universo desta pesquisa se constituiu de 20 estudantes trabalhadores, que estão cursando o Ensino Fundamental II, da modalidade da Educação de Jovens e Adultos.

O presente estudo pautou-se na abordagem qualitativa de pesquisa, desenvolvida por meio da pesquisa de campo utilizando como instrumento de recolha dos dados a observação indireta através da roda de conversa com um roteiro medianamente estruturado, objetivando obter informações sobre a visão dos estudantes da Escola Maria Áurea Pimentel Ferreira (EMAPF) sobre os motivos e as possibilidades da utilização do aparelho celular nas aulas da EJA. Durante o bate papo na roda de conversa, os sujeitos interviram na produção da informação. Como instrumento de observação direta, foram utilizados durante a aplicação das oficinas, notas de campo e registros fotográficos feito com aparelho celular, onde os pesquisadores fizeram a recolha das informações, sem se dirigir aos sujeitos interessados.

A primeira questão da roda de conversa ajudou-nos diagnosticar se os estudantes possuíam celulares. Entre os vinte estudantes pesquisados apenas dois não possuem celulares, ou seja, o celular faz parte da vida dos estudantes da EJA. Dos que possuem celulares 70\% estão na faixa etária de 16 aos 25 anos, 30\% de indivíduos de 30 a 35 anos e os que não possuem celulares estão na faixa etária de 35 a 50 anos. É interessante observar que o aparelho celular está nas mãos dos mais jovens, comprovando a importância do celular no cotidiano dos jovens na construção da sua identidade.

Dos aparelhos que costumam levar para escola, todos indicaram possuir celular ou smartphone, além de outras combinações. Entre as marcas de celular utilizadas pelos sujeitos encontramos: Apple, LG, Motorola, Multilaser, Nokia, Samsung, Sony Ericsson. Então, verificamos que eles fazem opção pelos celulares mais caros e de última geração, por serem jovens e com poucas reponsabilidades no orçamento doméstico investem os seus "mínimos" salários na compra desses celulares. Para revelar um dos significados simbólicos dos participantes da pesquisa sobre o uso de telefones celulares caros e de alta tecnologia, destacamos a fala de um estudante jovem “(...) possuir estes celulares gera prestígio e dá entender que você tem uma certa condição social, as pessoas olham primeiro para as marcas e depois para as pessoas". Também, identificaram que o celular estaria associado ao 
sentimento de pertencimento ao grupo. Nestas situações apresentadas, percebemos que o consumo opera símbolos de prestígio, reconhecimento, aceitação e que definiriam o pertencimento a uma determinada classe pela "personalização" do próprio aparelho (através do design, tamanho, cor das tampas, marcas).

Quanto ao uso dos celulares em sala de aula, os que possuem celulares declararam utilizar o celular em sala de aula, mesmo que sem a permissão do professor. Os principais sites/aplicativos utilizados foram os relacionados no quadro a seguir:

Quadro1 - Porcentagem dos principais sites/aplicativos utilizados pelos estudantes da EJA $30 \%$ dos jovens revelaram utilizar os jogos

$25 \%$ dos jovens citaram watsapp como mais utilizado

$20 \%$ dos participantes da pesquisa disseram que utilizam mais o facebook $10 \%$ declararam utilizar o Youtube

$5 \%$ afirmaram que o mais utilizado é o Instagram

$5 \%$ fizeram referência ao Twiter

$5 \%$ utilizam com mais frequência o E-mail.

Fonte: autoria própria, 2015

Como podemos observar no quadro acima, os jogos são os principais aplicativos utilizados pelos estudantes. Entretanto, este aplicativo não é aproveitado pela maioria dos docentes por considerá-los como passatempo, sem valor pedagógico, sem finalidade educativa por apresentar caráter "não- sério", ou seja, estes educadores desconhecem o real significado e importância para o desenvolvimento dos jovens e como estes poderiam ser aproveitados para interligar os jogos ao conteúdo, favorecer o avanço da linguagem, do pensamento e da concentração. Sendo assim, é importante apreender o que motiva os jovens no uso dos sites/aplicativos para o entendimento de como estes podem servir de base para o processo ensino-aprendizagem.

Além disso, foram questionados sobre a utilização dos recursos tecnológicos nas aulas da EJA pelos professores, dentre os mais citados, observam-se:

Quadro 2 - Porcentagem sobre a utilização dos recursos tecnológicos nas aulas de EJA $25 \%$ afirmaram que os recursos são utilizados como suporte para ampliação e discussão de uma temática, como por exemplo vídeos, documentários, filmes

$15 \%$ declararam que os recursos são utilizados para ilustrar as aulas, como Datashow, Power point. $60 \%$ disseram que poucos professores utilizam recursos tecnológicos

Fonte: autoria própria, 2015

Por outro lado, $80 \%$ dos estudantes defendem que os professores deveriam utilizar recursos tecnológicos na sala da EJA e também liberar o uso de aparelhos eletrônicos, 
porque os que têm estes aparelhos usam de alguma forma; $15 \%$ discordam deste uso e 5\% não quis opinar. A maioria dos estudantes ouvidos na roda de conversa (95\%) reconhece que as aulas da EJA poderiam ser mais motivadoras se tanto professores quanto os estudantes utilizassem melhor a tecnologia, inclusive no laboratório de Informática, disponível na escola.

\section{A VIVÊNCIA DO USO DO APARELHO CELULAR COMO RECURSO DIDÁTICO PARA MEDIAR A CONSTRUÇÃO DO CONHECIMENTO NA EJA}

A principal motivação para a construção deste projeto nasceu da procura de respostas para a utilização do aparelho celular como aliado nas aulas da EJA. Existe uma diversidade de atividades que podem ser realizadas utilizando o celular, entre as atividades destacadas no trabalho, estão: pesquisa, coleta de imagens, coleta de músicas, criação de gráficos, criação de vídeos. A seguir, aparecem sinteticamente, as atividades realizadas durante as oficinas.

A atividade começa com a oficina "A ética no uso da tecnologia". As Novas Tecnologias da Informação e Comunicação, trouxeram facilidades e conforto ao dia-a-dia e também alguns problemas, tais como os dilemas éticos surgidos durante seu uso.

Durante a oficina, propomos o confronto do aluno com situações e contextos que exijam que ele manifeste opiniões, assuma posições, elabore argumentos sobre as situações apresentadas que discutiam a questão do comportamento padrão de compartilhar tudo, sem muita análise sobre a pertinência desta ação em determinados contextos. É responsabilidade da escola através da reflexão e da ação demonstrar a importância do respeito ao outro.

Na sequência preparamos a segunda oficina, intitulada "Ateliê de produções" - A proposta era que os estudantes produzissem textos "minicontos" sobre o uso da tecnologia. Estimulou-se a pesquisa e a interação com os outros autores e ilustradores, através de sites de relacionamentos e pesquisa no Google através dos celulares presentes na sala de aula. Todos os estudantes pesquisaram, ilustraram e criaram um miniconto com o apoio do celular e que foram apresentados pelos próprios estudantes no "Sarau Literário da EJA", com imagens registradas desse momento.

A terceira oficina, sugerida pelos estudantes, intitulada "Nossas músicas, nossas identidades", sugestionamos que os estudantes apresentassem as músicas que eles escutam na escola nos aparelhos celulares durante as aulas, mesmo sem a autorização dos professores. Cada estudante apresentava a música de sua preferência, utilizando o seu aparelho celular, ouvíamos as músicas e discutíamos o que era dito nas letras. Conforme demonstrávamos interesse em ouvir os que estudantes escutavam, eles foram trazendo mais 
músicas. Em alguns desses momentos, o grupo se juntava para cantar as músicas em coro, alguns dançavam. Observa-se que a música é um recurso encontrado pelos jovens para afirmarem sua identidade na escola, fazendo-se ouvidos por suas músicas. No segundo momento, foi solicitado que os estudantes preparassem gráficos com as músicas apresentadas para facilitar a análise e interpretação do conjunto de dados. Com a existência de diversos tipos de gráficos, os estudantes foram orientados a fazerem uma pesquisa sobre esta diversidade. A pesquisa foi realizada com o apoio do telefone celular. Após a conclusão da pesquisa, realizamos uma discussão sobre as diferentes representações gráficas e cada grupo apresentou o gráfico elaborado apresentando as músicas escolhidas pela turma.

A quarta oficina, "Fazendo o nosso filme", o trabalho evoluiu da seguinte forma, foi passado para os celulares dos estudantes por Bluetooth fotos retiradas durante os diversos projetos realizados na escola, objetivando escolher as fotografias que seriam utilizadas no vídeo. Após a seleção das fotografias, enviamos estas imagens para o notebook da escola, onde foi montado o vídeo através do Windows Movie Maker (que é um editor de filmes gratuito. Com ele, o usuário pode criar, editar e compartilhar seus filmes diretamente do computador). Os próprios alunos montaram o vídeo, pois muitos dominam o acesso as tecnologias, o vídeo destaca as principais atividades realizadas pelos estudantes e professores da EJA, com sonorização musical (uma das músicas apresentadas por eles na terceira oficina), mostrando os resultados dos trabalhos realizados no ano de 2015. O Vídeo foi exibido no encerramento das atividades letivas do ano de 2015, o "FESTEJA - Encerrando ciclos e iniciando novas etapas" que representa o encerramento do Ensino Fundamental II para os estudantes que concluíram este Percurso Formativo.

\section{AVALIANDO SUAS IMPLICAÇÕES NA ESCOLA MUNICIPAL MARIA ÁUREA PIMENTEL FERREIRA}

A proposta apresentada foi bem aceita pelos estudantes da EJA, todos participaram, demonstrando interesse e interagiram de maneira produtiva e responsável no desenvolvimento das atividades propostas, respeitando o ritmo e o tempo, as habilidades, as potencialidades e as dificuldades dos jovens e adultos, possibilitando que cada um encontrasse o seu caminho. Observamos a habilidade que os estudantes mais jovens possuem para utilização da tecnologia, neste caso em especial o aparelho celular e como cada jovem contribui com suas ideias e criatividade para o acesso dos mais velhos a esta tecnologia, entre outros resultados expressivos. 
$\mathrm{Na}$ avaliação realizada com os estudantes sobre a experiência do uso do celular na sala de aula, muitos declararam que o projeto superou as expectativas e os preconceitos com relação ao uso do celular na construção do conhecimento de Jovens e Adultos.

Os dados coletados, demonstram que os estudantes possuem celulares e que carregam estes a todo momento, uma realidade que não pode ser ignorada pelos gestores e professores, pois o uso destes aparelhos hoje faz parte da construção da identidade juvenil. Cabe aos gestores e professores, compreenderem culturalmente o que significa o uso e a prática social dos estudantes da EJA com os seus respectivos celulares, tendo que coordenar os desdobramentos do uso do celular em sala de aula, desenvolver projetos, atividades que possam contribuir para aprendizagem dos estudantes da EJA.

Fica evidente, nos estudos realizados que a tecnologia da informação e comunicação fazem parte da vida dos jovens e adultos e por isso mesmo, devemos utilizá-la a nosso favor, para envolver o estudante com seu processo de aprendizagem, reconhecendo seus conhecimentos e suas experiências. Outra questão, é que as escolas públicas sofrem pela falta de estrutura e recursos tecnológicos que poderiam ser supridos pelo uso dos aparelhos celulares que os estudantes carregam e que com vimos anteriormente, dispõem de uma infinidade de funções.

É imprescindível ainda, que os professores trabalhem para que essa tecnologia possa ser utilizada de forma, responsável, consciente e ética. É uma tarefa difícil, mas através da prática realizada na EJA, constatamos que é possível realizar atividades utilizando o aparelho celular na sala de aula e que este é um bom aliado na escola se for direcionado corretamente. Este relato de experiência não apresenta todas as possibilidades do uso do celular como recurso didático, deixando como possibilidade de pesquisa para trabalhos futuros.

\section{REFERÊNCIAS}

Agencia Nacional de Telecomunicações (2017). Disponível em: http://www.anatel.gov.br/Portal/exibirPortalInternet.do. Acesso em: 10 fev. 2017.

ANTONIO, José Carlos. Uso pedagógico do telefone móvel (Celular), Professor Digital, SBO, 13 jan. 2010. Disponível em: http://professordigital.wordpress.com/2010/01/13/usopedagogicodo-telefone-movel-celular/. Acesso em: 15 fev. 2017.

CASTEllS, M. et al. Mobile Communication and Society: A Global Perspective. Cambridge: MIT Press, 2009. 
CORTÊS, H. A importância da tecnologia na formação de professores. Revista Mundo Jovem, Porto Alegre, n. 394, março de 2009, p.18.

COSTA, Jeremias Ferreira, et al. $O$ celular e o ensino de ondas na escola: uma proposta preliminar. Congresso Internacional TIC e Educação. UFPR, (s.d). Disponível em: http://ticeduca.ie.ul.pt/atas/pdf/369.pdf. Acesso em 19 de nov. 2019.

FREIRE, Paulo. Educação e mudança. São Paulo: Paz e Terra, 2008.

MORAN, José Manuel. A educação que desejamos: novos desafios e como chegar lá. São Paulo: Papirus, 2008.

RIBAS, Arilson et al. Possibilidade de usar o telefone celular como ferramenta educacional para mediar práticas de ensino de física: uma revisão de literatura. Simpósio Nacional de Ciências e Tecnologias. Ponta Grossa, UFPR,2012. Disponível em: www.sinect.com.br/2012/down.php?id=2855\&q=1. Acesso em: 19 de fev. 2017.

SOUZA, R. A. Comunicação mediada pelo computador: o caso do chat. In: In: C. V. Coscarelli (ed.). Novas tecnologias, novos textos, novas formas de pensar. 3. ed. Belo Horizonte: Autêntica, 2009. p. 111-118.

SILVEIRA, Sérgio Amadeu. Redes cibernéticas e tecnologias do anonimato. Comunicação \&Sociedade. v. 1, p.113-134, 2009. 